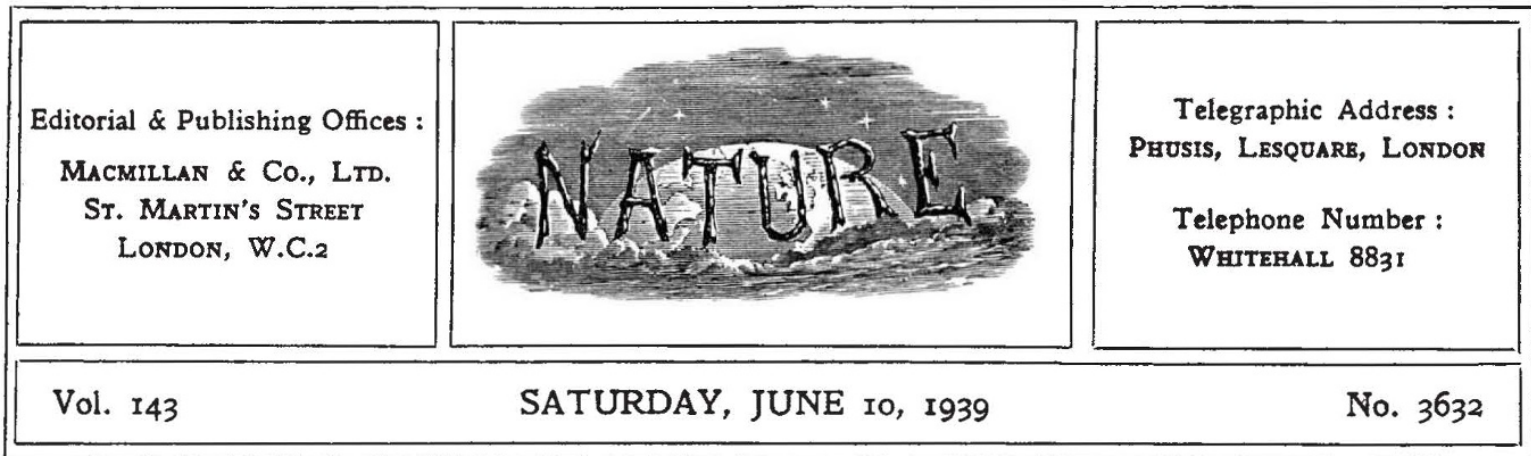

\title{
Planning in House and City
}

W

HILE we may acquiese in the necessity at the present time of concentrating effort on the gigantic task of national defence, we are nevertheless acutely aware that much is seriously amiss with a civilization in which such use of scientific effort should be necessary. On the credit side, however, it will be granted that the importance of social factors in industrial and national problems is widely recognized both within and without the ranks of scientific workers themselves, and the necessity for reorientation of research effort between the biological and social sciences and the physical sciences now appears to command general assent. There are, moreover, indications that at last some of the new powers that science has put at our disposal are beginning to find expression in ways appropriate to their purpose and less dominated by traditions or ideas of the past. True it is that the development of aviation remains warped by military ideas and demands, but the development of the motor-car, for example, is at last finding expression in its own appropriate forms rather than those dictated by the functions or purpose of the horse-drawn vehicle. Similarly in architecture, there have been some striking examples of the use of the newer materials, free from limitations imposed by traditional ideas or practice.

None the less, it has to be admitted that progress on the whole has been comparatively slight, and it is in the changed attitude to new ideas rather than in actual achievement that the strongest reasons for hope are to be found. When, for example, such a radical proposal as the removal of population from a derelict area like that of Merthyr Tydfil to an entirely new but more suitable site, which offers the community a prospect of economic development, can be seriously considered instead of being derided or rejected out of hand, progress is being made. The keen interest which is being taken in the location of industry has, of course, been stimulated by the PEP report and by the evidence given before the Royal Commission on the Geographical Distribution of the Industrial Population, but these two inquiries are really the outcome of public consciousness of the importance of this problem.

There are, however, few, if any, problems arising out of the transformation of industry and society under the influence of mechanical science, in which there is greater need for bold and radical action and for the discovery of more appropriate forms of expression for the new forces at our disposal, than in those arising out of the housing of the community, whether in the aspect of building, town planning, the location of industry or provision of services and amenities.

An imaginative contribution to fundamental thinking about the whole problem of the modern city, whether from the point of view of amenities, industry, defence or housing, has been provided by Mr. Lewis Mumford in "The Culture of Cities"*. He makes a strong plea for casting aside all preconceived ideas and for a determined attempt to think out the real purposes which a city, whether as a whole or in the individual units of houses, is intended to serve in the conditions of to-day and with the resources which are at our disposal.

Even those who do not instinctively recognize that, in this way alone is possible a scientific approach to the problem of really effective planning, cannot but be impressed by the picture

- The Culture of Cities. By Lewis Mumford. Pp. xii $+586+32$ plates. (London : Martin Secker and Warburg, Ltd., 1988.) 21s. net. 
which Mr. Mumford gives of the evils which have in the past resulted from unco-ordinated development, the clinging to obsolete methods of construction or attempting to force new materials into the forms used for earlier products and other purposes. Again and again, advances of earlier generations have crystallized in hard forms which prove intractable obstacles to the progress of later generations, and rob them of many of the advantages placed within their reach by progressive knowledge.

The appeal which Mr. Mumford makes in his latest book is for vision and a sense of values. He would have us examine the institutions which make up city life, from the individual household to the school, the scientific society, the church, and determine the exact functions which they are required to fill in the light of medical knowledge to-day, the advances in means of communication, whether of transport or in such fields as the telephone or broadcasting. Too often we maintain forms or institutions long after the needs for which they were originally created have disappeared or are met more effectively in some other way.

It is easy to overlook the exact social significance of some of these changes. Until, however, we realize that the new means of transport and power production, with the telegraph, the telephone, the radio, the teleprinter and television, have enlarged the sphere of activity and at the same time diminished the need for physical movement and close settlement, we cannot begin to determine accurately the functions and needs of city life; and time, energy, money, and human vitality will continue to be expended in activities of no intrinsic value, as in the crowded transport systems of every metropolis and even in other public services such as water and sewage disposal.

Clear-cut conceptions of the purposes our institutions are to serve in this age, not merely in the age in which they were originally designed, form the basis of adequate planning. Of the dwelling-house we must recognize, as Mr. Mumford points out, that certain of its functions, though domestic in origin, may be better served by communal institutions; for example, child-birth and the care of infective illnesses, weddings and funerals. Other functions, notably on the recreational side, have gained in importance, through the advent of radio, television and the telephone, and will continue to do so as leisure develops. When we have agreed on the exact functions which the modern dwelling-house is intended to serve, we can begin its rational design and eliminate many of the conventional requirements which no longer serve these functions. Moreover, we shall then be free to form an unbiased judgment as to the use which can be made of the new materials at our disposal, the possibilities in the way of fabrication of floors, roof and the walls, and the proportioning of mechanical services or utilities and space or storage.

Treatment of the housing problem along such lines as these demands creative as well as scientific thought. Vision and some ordered conception of family and civic life are also demanded, and this is no less true of other civic institutions such as the school, the church, the public assembly hall, the library, and the scientific or literary society. Definite objectives must be visualized in the provision of the best possible environment for human nuture and culture, the priority of consuming and creative activities over mechanical processes and the expression of vital standards in terms of leisure, health, biological activity, æsthetic pleasure and social opportunity. One of the great dangers of the present moment is that the opportunities which the necessities of defence impose upon us of altering both the design and construction of towns and cities should be missed or stereotyped for lack of imagination.

Mr. Mumford, discussing the new functions of the city, suggests that under the new conditions it should become, as it has often been in the past, the chief instrument of education, and that what should distinguish the new community is not so much the introduction of any essentially new institution as their adequate organization and incorporation as an essential part of the whole. He urges accordingly that cities should be deliberately designed to serve those purposes, and that their size should be a function of the social relation. ship to be served.

Essentially we have here a positive conception, in place of the merely negative one, which has already led to the recognition that definite steps must be taken to prevent the continued industrial expansion warping or enfeebling the life of the rest of the country. Moreover, it is a conception which guides the planning of the whole of society. Economy must be a regulating principle in all design, for it is only by saving on the means and instruments of life that a community can command the necessary abundance at the higher levels of art, science and education. A modern plan must embrace every human need appropriate to the 
structure without waste of space, duplication, or clumsy and indifferent means of circulation.

It follows from this that a first task in the planning and survey required is to educate citizens, to give them the tools of action and to prepare the stage as well as to suggest the socially significant objectivities. Ultimately, this is an essential duty of every school and especially every university. With it there must go the further utilization of science through the regional survey, regional exploration and regional construction, if we are to increase the area of rational human control. Nor should our inability to devise at once the appropriate structure for our civilization, as Mr. Mumford further reminds us, be a cause for permanent discouragement. Most of the forces working towards international co-operation are young, while the opposing forces are old and deeply ingrained in institutions and organizations. A generation is too short a space of time for the reorganization of modern society, whether within or across national frontiers.

If therefore we should not be too readily discouraged at the rate of progress, the problem is too urgent for any opportunity to be neglected. Even while citizens are being educated to appreciate the need for imaginative reconstruction, further obstacles to progress are continually crystallizing out, amenities are disappearing and the problem threatens to become more formidable and intractable. The Bressey report on Highway Development Survey (Greater London) provides already a classic example of the consequences of procrastination or neglect in such matters. Scientific workers undoubtedly have a great part to play in the development of the new and appropriate forms in which the forces they have placed at man's disposal can be utilized for the most effective service of the needs of the community. The achievement of that ideal of fitness for the purpose demands equally, however, the co-operation of art and the humanities, and we may well hope that the very urgency of the present threats to all the richest treasures of our heritage may yet stimulate that co-operation, and issue in the creative expression of a new culture worthy to be compared with any recorded in the long history of mankind.

\section{History and Scientific Endeavour}

\section{The Cambridge Ancient History}

Vol. 12: The Imperial Crisis and Recovery, A.D. 193-324. Edited by Dr. S. A. Cook, F. E. Adcock, M. P. Charlesworth, N. H. Baynes. Pp. xxvii +849 . 35s. net. Volume of Plates 5. Prepared by C. T. Seltman. Pp. $x \nabla+243$. 15s. net. (Cambridge: At the University Press, 1939.)

$\mathrm{T}$ HE issue of the twelfth and last volume of the Cambridge Ancient History is so notable an event that a word must be said about the whole enterprise and the way in which the two ancient universities of Great Britain have divided the work of learning between them. Something must also be added, more especially appropriate to this review, about the point of view from which the man of science is inevitably driven to regard the study of history as a whole.

First as to Oxford and Cambridge. While Cambridge has been elaborating this series of forty volumes on ancient, medieval and modern history, Oxford has given us the standard dictionary of the English language and has just completed a revised and enlarged Greek dictionary based on and improving the traditional "Liddell and Scott".
Of these works we have nothing to say at the moment, except that the division of labour speaks well for the co-operation of the two learned bodies concerned and throws a cheering light on the industry and power of organization of both.

The histories which Cambridge has just completed have also a memorable connexion with one of the most learned men whom Great Britain has ever produced. Lord Acton, in 1896, the year after his appointment as regius professor of modern history at Cambridge, was approached by the syndics of the University Press with a suggestion that he should undertake the direction of a history of the world. They can proudly claim that the idea first came from them. Acton replied modestly that such a work was beyond the capacity of any one man. A syndicate of learning was the only conceivable method; but before the end of that year he had himself accepted the editorship of the modern section and had drawn up a plan which the Press approved. He got together a team of assistant editors and contributors and impressed them with his ideals. He died in 1902, the year of the appearance of the first volume. The last of the twelve appeared in 1910, and became at 